\title{
A Hybrid of Fuzzy and Fuzzy Self-Tuning PID Controller for Servo Electro-Hydraulic System
}

\author{
Kwanchai Sinthipsomboon, Issaree Hunsacharoonroj, Josept Khedari, \\ Watcharin Po-ngaen and Pornjit Pratumsuwan
}

Additional information is available at the end of the chapter

http://dx.doi.org/10.5772/48614

\section{Introduction}

The application of hydraulic actuation to heavy duty equipment reflects the ability of the hydraulic circuit to transmit larger forces and to be easily controlled. It has many distinct advantages such as the response accuracy, self-lubricating and heat transfer properties of the fluid, relative large torques, large torque-to-inertia ratios, high loop gains, relatively high stiffness and small position error. Although the high cost of hydraulic components and power unit, loss of power due to leakage, inflexibility, nonlinear response, and errorprone low power operation tends to limit the use of hydraulic drives, they nevertheless constitute a large subset of all industrial drives and are extensively used in the transportation and manufacturing industries (Merrit, 1976; Rong-Fong Fung et al, 1997; Aliyari et al, 2007).

The Servo Electro-hydraulic System (SEHS), among others, is perhaps the most important system because it takes the advantages of both the large output power of traditional hydraulic systems and the rapid response of electric systems. However, there are also many challenges in the design of SEHS. For example, they are the highly nonlinear phenomena such as fluid compressibility, the flow/pressure relationship and dead-band due to the internal leakage and hysteresis, and the many uncertainties of hydraulic systems due to linearization. Therefore, it seems to be quite difficult to perform a high precision servo control by using linear control method Rong-Fong Fung et al, 1997; Aliyari et al, 2007; Pratumsuwan et al, 2010).

Classical PID controller is the most popular control tool in many industrial applications because they can improve both the transient response and steady state error of the system at the same time. Moreover, it has simple architecture and conceivable physical intuition 
of its parameter. Traditionally, the parameters of a classical PID controller, i.e. $K_{P}, K_{I}$, and $K_{D}$, are usually fixed during operation. Consequently, such a controller is inefficient for control a system while the system is disturbed by unknown facts, or the surrounding environment of the system is changed (Panichkun \& Ngaechroenkul, 2000; Pratumsuwan et al, 2010).

Fuzzy control is robust to the system with variation of system dynamics and the system of model free or the system which precise information is not required. It has been successfully used in the complex ill-defined process with better performance than that of a PID controller. Another important advance of fuzzy controller is a short rise time and a small overshoot (Aliyari et al, 2007; Panichkun \& Ngaechroenkul, 2000). However, PID controller is better able to control and minimize the steady state error of the system. To enhance the controller performance, hybridization of these two controller structures comes to one mind immediately to exploit the beneficial sides of both categories, know as a hybrid of fuzzy and PID controller (Panichkun \& Ngaechroenkul, 2000; Pratumsuwan et al, 2010).

Nevertheless, a hybrid of fuzzy and PID does not perform well when applied to the SEHS, because when the SEHS parameters changes will require new adjustment of the PID gains. A hybrid of fuzzy and fuzzy self-tuning PID controller is proposed in this paper. The proposed control scheme is separated into two parts, fuzzy controller and fuzzy self-tuning PID controller. Fuzzy controller is used to control systems when the output value of system far away from the target value. Fuzzy self-tuning PID controller is applied when the output value is near the desired value. In terms of adjusting the PID gains tuning using fuzzy as to obtain an optimum value.

\section{Servo electro-hydraulic system}

The physical model of a nonlinear servo electro-hydraulic system is shown in Figure 1.

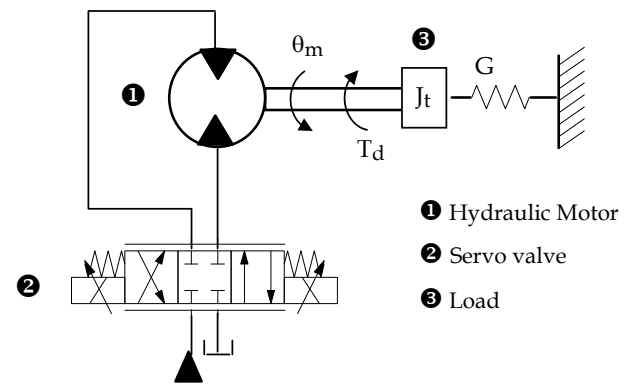

Figure 1. The physical model of a servo electro-hydraulic system.

The inertial-damping with a nonlinear torsional spring system is driven by a hydraulic motor and the rotation motion of the motor is controlled by a servo valve. Higher control input voltage can produce larger valve flow from the servo valve and fast rotation motion of 
the motor. The entire system equations are described as follows. The servo valve flow equation (1) is described as:

$$
Q_{L}=K_{q} x_{v}-K_{c} P_{L}
$$

where $Q_{L}$ is the load flow, $X_{v}$ is the displacement of the spool in the servo valve, $K_{c}$ is the flow-pressure coefficient, $P_{L}$ is the load pressure, and $K_{q}$ is the flow gain which varies at different operating points. $K_{q}$ is given by

$$
K_{q}=C_{d} w \sqrt{\frac{\left(P_{S}-P_{L}\right) \operatorname{sgn}\left(X_{v}\right)}{\rho}}
$$

where $C_{d}$ is the discharge coefficient, $w$ is the area gradient, $\rho$ is the fluid mass density, and $P_{S}$ is the supply pressure.

The continuity equation to the motor is formulated as

$$
Q_{L}=D_{m} \dot{\theta}_{m}+C_{l} P_{L}+\frac{V_{t}}{4 \beta_{e}} \dot{P}_{L}
$$

where $D_{m}$ is the volumetric displacement, $\dot{\theta}_{m}$ is the angular velocity of the motor shaft, $C_{l}$ is the total leakage coefficient of the motor, $V_{t}$ is the total compressed volume, and $\beta_{e}$ is the effective bulk modulus of the system.

Substituting (1) into (3) leads to

$$
K_{q} X_{v}=D_{m} \dot{\theta}_{m}+K_{l} P_{L}+\frac{V_{t}}{4 \beta_{e}} \dot{P}_{L}
$$

where $K_{l}=K_{c}+C_{l}$ is the total leakage coefficient of the hydraulic system.

The torque balance equation for the motor is described as follows:

$$
P_{L} D_{m}=J_{t} \ddot{\theta}_{m}+B_{m} \dot{\theta}_{m}+G\left(\theta_{m}+G_{n} \theta_{m}^{3}\right)+T_{d}
$$

where $J_{t}$ is the total inertial of motor and load, $B_{m}$ is the viscous damping coefficient of the load, $T_{d}$ is the disturbance of the system, and $G_{n} \theta_{m}^{3}$ is the nonlinear stiffness of the spring.

From (1) to (5), the hydraulic servomechanism system equation can be described by a state equation as follows:

$$
\begin{aligned}
\dot{X}_{1} & =X_{2} \\
\dot{X}_{2} & =X_{3} \\
\dot{X}_{3} & =-\sum_{i=1}^{3} a_{i} X_{i}+b U-N(X, t)-d(t) \\
\dot{Z} & =r-X_{1}
\end{aligned}
$$


where

$$
\begin{aligned}
X(t) & =\left[X_{1}(t) X_{2}(t) X_{3}(t)\right]^{T}=\left[\theta_{m}(t) \dot{\theta}_{m}(t) \ddot{\theta}_{m}(t)\right]^{T} \\
a_{1}(t) & =\frac{4 \beta_{e}}{V_{t}} \frac{K_{l t}}{J_{t}} G \\
a_{2}(t) & =\frac{4 \beta_{e}}{V_{t}} \frac{D_{m}^{2}}{J_{t}}+\frac{4 \beta_{e}}{V_{t}} \frac{K_{l t}}{J_{t}} B_{m}+\frac{G}{J_{t}} \\
a_{3}(t) & =\frac{4 \beta_{e}}{V_{t}} K_{l t}+\frac{B_{m}}{J_{t}} \\
b(X) & =\frac{4 \beta_{e}}{V_{t}} \frac{D_{m}}{J_{t}} K_{q} K_{V} \\
N(x, t) & =\frac{4 \beta_{e} K_{l t} G_{n}}{V_{t} J_{t}} G X_{1}^{3}+\frac{3 G_{n}}{J_{t}} G X_{1}^{2} X_{2} \\
d(t) & =\frac{4 \beta_{e}}{V_{t}} \frac{K_{l t}}{J_{t}} T_{d}+\frac{1}{J_{t}} T_{d}
\end{aligned}
$$

in which $N(X, t)$ represents the nonlinear terms of the system.

\section{System descriptions}

We are considering a PC-based speed control of the SEHS that will use either a hybrid fuzzy PID or a hybrid of fuzzy and fuzzy self-tuning PID controller. The motor speed of this system is controlled. In order to construct fair test case for comparing both controllers, the experiments are constructed based on the same hardware elements. The specifications of this system are depicted in Table 1 and Figure 2 respectively.

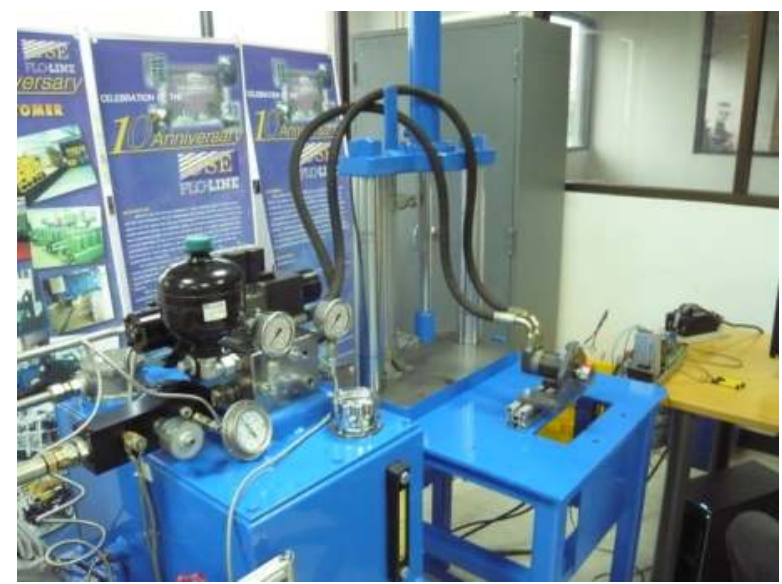

Figure 2. Experimental Setup. 


\begin{tabular}{|c|c|}
\hline Elements & Descriptions \\
\hline Hydraulic Motor & $\begin{array}{l}\text { Geometric displacement } 19.9 \mathrm{~cm}^{3} \\
\text { Max. Speed } 1000 \mathrm{rpm} \text {, Max. torque } 25 \mathrm{Nm} \\
\text { Max. pressure drop 100bar } \\
\text { Max. oil flow 20l/min }\end{array}$ \\
\hline Proportional valve & $\begin{array}{l}\text { directly actuated spool valve, grade of filtration } 10 \mu \mathrm{m} \text {, } \\
\text { nominal flow rate } 601 / \mathrm{min} \text { (at } \Delta \mathrm{p}_{\mathrm{N}}=6.9 \mathrm{bar} / \text { control edge), } \\
\text { nominal current } 1600 \mathrm{~mA} \text {, repeatability }<1 \% \text {, hysteresis }<5 \%\end{array}$ \\
\hline Pump (supply pressure) & 100 bar \\
\hline Amplifier card & $\begin{array}{l}\text { set point values } \pm 5 \mathrm{VDC} \text {, solenoid outputs (PWM signal) } 24 \\
\mathrm{~V} \text {, dither frequency } 200 \mathrm{~Hz} \text {, max power } 45 \mathrm{~W} \text {. }\end{array}$ \\
\hline Encoder & $8 \mathrm{c} / \mathrm{t}, \mathrm{I}$ (optical shaft encoder) \\
\hline DAC & Resolution 15 bit DAC, output $0-10 \mathrm{~V}$ \\
\hline DAQ Card NI 6221 PCI & $\begin{array}{l}\text { analog input resolutions } 16 \text { bits (input range } \pm 10 \mathrm{~V}) \text {, output } \\
\text { resolutions } 16 \text { bits (output range } \pm 10 \mathrm{~V}), 833 \mathrm{kS} / \mathrm{s}(6 \mu \text { s full- } \\
\text { scale settling) }\end{array}$ \\
\hline $\begin{array}{l}\text { Operating systems \& } \\
\text { Program }\end{array}$ & Windows XP, and LabVIEW 8.6 \\
\hline
\end{tabular}

Table 1. Specifications of the SEHS.

\section{Controller designs}

A closed loop system, whither the reference signal is set manually or automatically, can perform control of motor speed. Figure 3 represents typical of an "Automatic Closed Loop" control system. As shown in the figure, the velocity of a hydraulic motor is controlled by a servo valve. The servo valve solenoid is receiving driving electrical current from an amplifier card, which is generating the driving current based on a control signal supplied by a controller. The controller responsibility is to continuously compare the reference signal and the actual motor speed feedback by the velocity sensor, after consequently generate the adequate control signal.

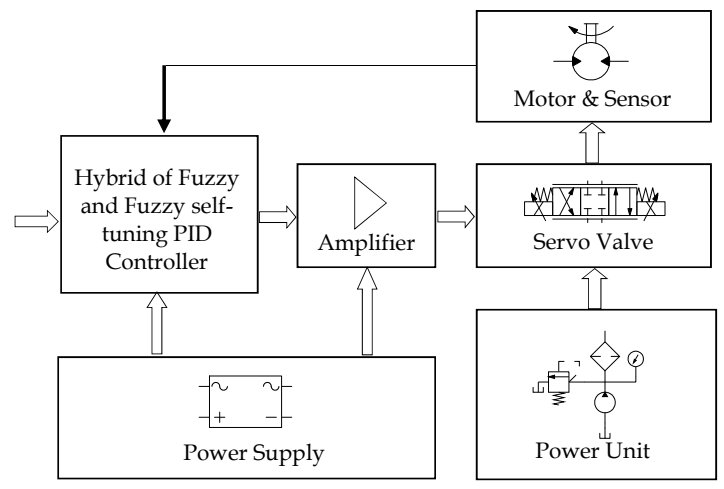

Figure 3. Block diagram of using a hybrid fuzzy and fuzzy self-tuning PID controls the SEHS. 
There are various types of control system used in classical control, modern control and intelligent control systems, each having been studied and implemented in many industrial applications. Every control system method has its advantages and disadvantages. Therefore, the trend is to implement hybrid systems consisting of more than one type of control technique.

\subsection{PID controller}

The PID control method has been widely used in industry during last several decades because of its simplicity. The implementation of PID control, as shown in (7), requires finding suitable values for the gain parameters $K_{P}, K_{I}$, and $K_{D}$. To tune these parameters, the model is linearized around different equilibrium points,

$$
u(k)=K_{p} e(k)+K_{I} \sum_{i=0}^{k} e(i)+K_{D}[e(k)-e(k-1)]
$$

where $e(k)$ is the error signal.

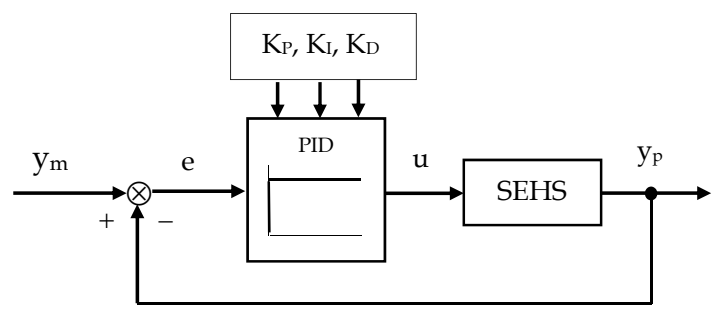

Figure 4. Block diagram of a PID controller.

However, the PID method is not suitable for controlling a system with a large amount of lag, parameter variations, and uncertainty in the model. Thus, PID control cannot accurately control velocity in a SEHS (Rong-Fong Fung et al, 1997; Aliyari et al, 2007).

\subsection{Fuzzy controller}

Fuzzy Control (FC) has the advantage that it does not require an accurate mathematical model of the process. It uses a set of artificial rules in a decision-making table and calculates an output based on the table (Aliyari et al, 2007; Panichkun \& Ngaechroenkul, 2000).

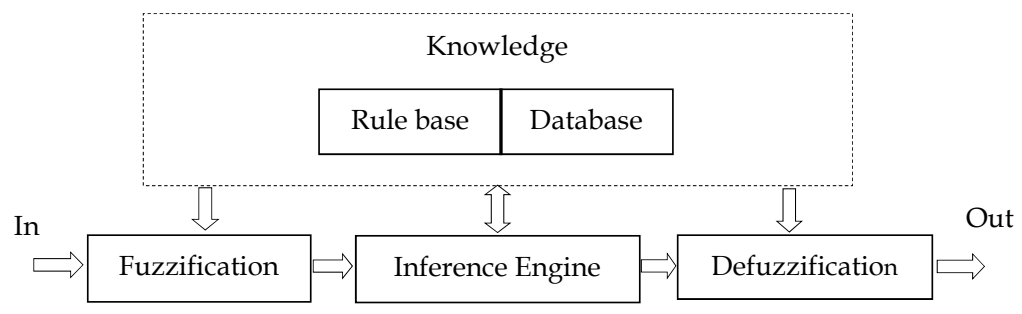

Figure 5. Structure of FC. 
Figure 5 \& 6 show a schematic diagram of a fuzzy control system. Input variables go through the fuzzification interface and are converted to linguistic variables. Then, a database and rule base holding the decision-making logic are used to infer the fuzzy output. Finally, a defuzzification method converts the fuzzy output into a signal to be sent out.

First, the two input variables must be defined in terms of linguistics. The error $(e)$ in velocity is expressed by a number in the interval from -10 to 10 . There are five linguistic terms of the error in velocity: negative big $(\mathrm{NB})$, negative $(\mathrm{N})$, zero $(\mathrm{Z})$, positive $(\mathrm{P})$, and positive big $(\mathrm{PB})$. Similarly, the fuzzy set of the error change of the velocity or acceleration $(\Delta e)$ is presented as $\{\mathrm{NB}, \mathrm{N}, \mathrm{Z}, \mathrm{P}, \mathrm{PB}\}$ over the interval from -10 to $10 \mathrm{~V}$. Finally, the fuzzy set of the output signal is presented as $\{\mathrm{NB}, \mathrm{N}, \mathrm{Z}, \mathrm{P}, \mathrm{PB}\}$ over the interval from -5 to $5 \mathrm{~V}$.

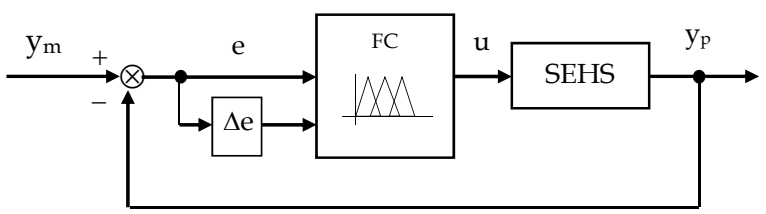

Figure 6. Block digram of a FC.

The knowledge base for a fuzzy controller consists of a rule base and membership functions. It is reasonable to present these linguistic terms by triangular-shape membership functions, as shown in Figure 6. A fuzzy control knowledge base must be developed that uses the linguistic description of the input variable. In this paper, an expert's experience and knowledge method is used to build a rule base (Zhang et al, 2004). The rule base consists of a set of linguistic IF-THEN rules containing two antecedences and one consequence, as expressed in the following form:

$$
R_{i, j, k}: \text { IF } \mathrm{e}=\mathrm{A}_{\mathrm{i}} \text { and } \Delta \mathrm{e}=\mathrm{B}_{\mathrm{j}} \text { THEN } \mathrm{u}=\mathrm{C}_{\mathrm{k}},
$$

where $1 \leq i \leq 5,1 \leq j \leq 5$, and $1 \leq k \leq 5$. The total number of IF-THEN rules is 25 and is represented in matrix form, called a fuzzy rule matrix, as shown in Table 2.

The decision-making output can be obtained using a max-min fuzzy inference where the crisp output is calculated by the center of gravity (COG) method.

\begin{tabular}{|l|l|l|l|l|l|}
\hline \multicolumn{1}{|r|}{$\mathrm{e}^{\Delta \mathrm{e}}$} & $\mathrm{NB}$ & $\mathrm{N}$ & $\mathrm{Z}$ & $\mathrm{P}$ & $\mathrm{PB}$ \\
\hline $\mathrm{NB}$ & $\mathrm{NB}$ & $\mathrm{NB}$ & $\mathrm{N}$ & $\mathrm{N}$ & $\mathrm{Z}$ \\
\hline $\mathrm{N}$ & $\mathrm{NB}$ & $\mathrm{N}$ & $\mathrm{N}$ & $\mathrm{Z}$ & $\mathrm{P}$ \\
\hline $\mathrm{Z}$ & $\mathrm{N}$ & $\mathrm{N}$ & $\mathrm{Z}$ & $\mathrm{P}$ & $\mathrm{P}$ \\
\hline $\mathrm{P}$ & $\mathrm{N}$ & $\mathrm{Z}$ & $\mathrm{P}$ & $\mathrm{P}$ & $\mathrm{PB}$ \\
\hline $\mathrm{PB}$ & $\mathrm{Z}$ & $\mathrm{P}$ & $\mathrm{P}$ & $\mathrm{PB}$ & $\mathrm{PB}$ \\
\hline
\end{tabular}

Table 2. Fuzzy Rules of a FC. 


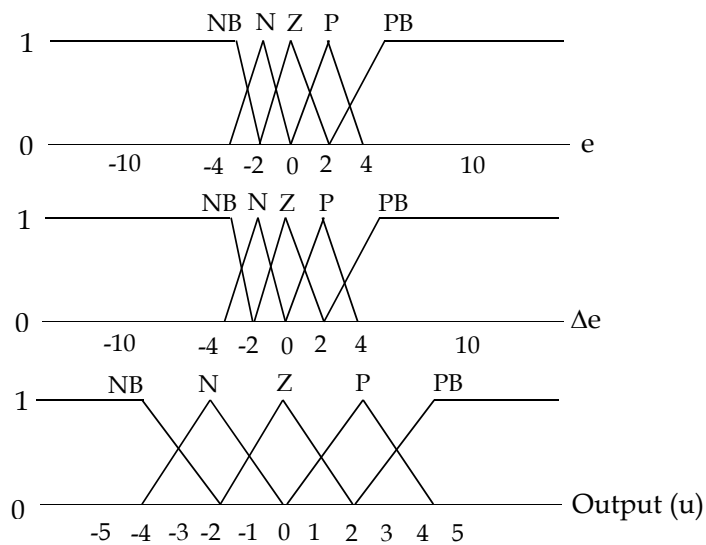

Figure 7. Fuzzy sets of a FC.

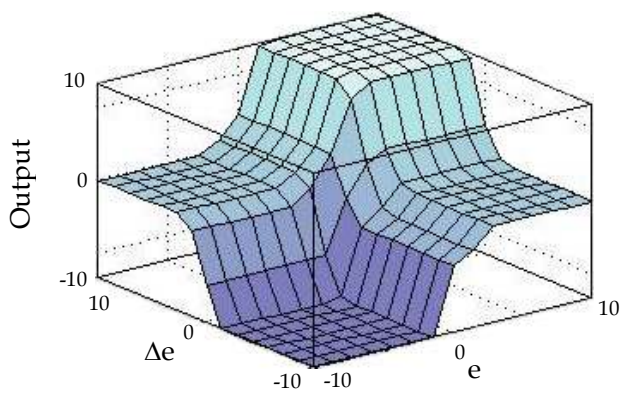

Figure 8. Input-output mapping of a FC.

\subsection{Hybrid of fuzzy and PID controller}

While conventional PID controllers are sensitive to variations in the system parameters, fuzzy controllers do not need precise information about the system variables in order to be effective. However, PID controllers are better able to control and minimize the steady state error of the system. Hence, a hybrid system, as shown in figure 9, was developed to utilize the advantages of both PID controller and fuzzy controller (Parnichkul \& Ngaecharoenkul, 2000; Erenoglu et al., 2006; Pratumsuwan et al., 2009;).

Figure 9 shows a switch between the fuzzy controller and the PID controller, where the position of the switch depends on the error between the actual value and set point value. If the error in velocity reaches a value higher than that of the threshold $e_{0}$, the hybrid system applies the fuzzy controller, which has a fast rise time and a small amount of overshoot, to the system in order to correct the velocity with respect to the set point. When the velocity is below the threshold $e_{0}$ or close to the set point, the hybrid system shifts control to the PID, which has better accuracy near the set velocity (Parnichkul \& Ngaecharoenkul, 2000; Erenoglu et al., 2006; Pratumsuwan et al., 2009;). 
Figure 9. Block diagram of a hybrid fuzzy PID controller.

\subsection{Fuzzy self-tuning PID controller}

Fuzzy self-tuning PID controller means that the tree parameters $K_{P}, K_{I}$, and $K_{D}$ of PID controller are tuned by using fuzzy tuner (Zhang et al, 2004; Song \& Liu, 2010; Zulfatman \& Rahmat, 2006; Feng et al, 2009). The coefficients of the conventional PID controller are not often property tuned for the nonlinear plant with unpredictable parameter variations. Hence, it is necessary to automatically tune the PID parameters. The structure of the fuzzy self-tuning PID controller is shown in Figure 10. Where $e$ is the error between desired velocity set point and the output, $e \Delta$ is the derivation of error. The PID parameters are tuned by using fuzzy tuner, which provide a nonlinear mapping from $e$ and $e \Delta$ of error to PID parameters.

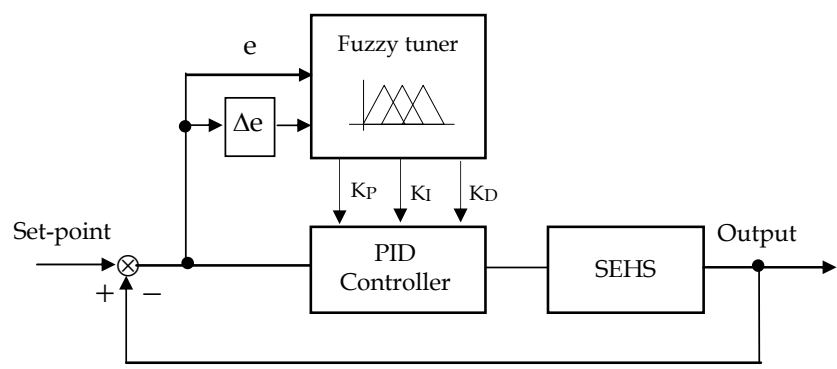

Figure 10. Block diagram of a fuzzy self-tuning PID controller.

Regarding to the fuzzy structure, there are two inputs to fuzzy inference: $e$ and $e \Delta$, and there outputs for each PID controller parameter $K^{\prime} P, K^{\prime} I$, and $K^{\prime} D$ respectively. Mamdani model is applied as structure of fuzzy inference with some modification to obtain the optimum value for $K_{P}, K_{I}$, and $K_{D}$. Suppose the variable ranges of the parameters of PID controller are $\left[K_{P \min }, K_{P \max }\right],\left[K_{I \min }, K_{I \max }\right]$, and [K $\left.K_{D \min }, K_{D \max }\right]$ respectively. The range of each parameters was determined based on the experimental on PID controls the SEHS. The range of each parameters are, $K_{P} \in[8,15], K_{I} \in[0.003,0.01]$, and $K_{D} \in[0.0001,0.000001]$. Therefore, they can be calibrated over the interval $[0,1]$ as follows: 


$$
\begin{aligned}
& K_{p}^{\prime}=\frac{K_{p}-K_{P_{\min }}}{K_{P \max }-K_{P \min }}=\frac{K_{P}-8}{15-8}, K_{p}=7 K_{p}^{\prime}+8 \\
& K_{I}^{\prime}=\frac{K_{I}-K_{I \min }}{K_{I \max }-K_{I \min }}=\frac{K_{I}-0.003}{0.01-0.003}, K_{I}=0.007 K_{I}^{\prime}+0.003 \\
& K_{D}^{\prime}=\frac{K_{D}-K_{D \min }}{K_{D \max }-K_{D \min }}=\frac{K_{D}-0.000001}{0.00001-0.000001}, K_{D}=0.0000009 K_{D}^{\prime}+0.000001
\end{aligned}
$$

The membership functions of these inputs fuzzy sets are shown in Figure 8. The linguistic variable levels are assigned as: negative big $(\mathrm{NB})$, negative $(\mathrm{N})$, zero $(\mathrm{Z})$, positive $(\mathrm{P})$, and positive big (PB). Similarly, the fuzzy set of the error change of the velocity or acceleration $(\Delta e)$ is presented as $\{\mathrm{NB}, \mathrm{N}, \mathrm{Z}, \mathrm{P}, \mathrm{PB}\}$. These levels are chosen from the characteristics and specification of the SEHS. The ranges of these inputs are from -10 to 10. Finally, whereas the membership functions of outputs $K^{\prime} P, K^{\prime}$, and $K^{\prime} D$ are shown in Fig. 8. The linguistic levels of these outputs are assigned as: negative big $(\mathrm{NB})$, negative $(\mathrm{N})$, zero $(\mathrm{Z})$, positive $(\mathrm{P})$, and positive big (PB) similarly where the ranges from 0 to 1 .

\begin{tabular}{|l|l|l|l|l|l|}
\hline & NB & N & $Z$ & P & PB \\
\hline NB & NB & NB & NB & N & Z \\
\hline N & NB & N & N & N & Z \\
\hline$Z$ & NB & N & Z & P & PB \\
\hline P & Z & P & P & P & PB \\
\hline PB & Z & P & PB & PB & PB \\
\hline
\end{tabular}

Table 3. Fuzzy Rules of KP Gain.

\begin{tabular}{|l|l|l|l|l|l|}
\hline & NB & N & Z & P & PB \\
\hline NB & PB & PB & PB & N & NB \\
\hline N & PB & P & P & Z & NB \\
\hline$Z$ & P & P & Z & N & NB \\
\hline P & Z & P & N & N & NB \\
\hline PB & Z & N & NB & NB & NB \\
\hline
\end{tabular}

Table 4. Fuzzy Rules of KI Gain.

\begin{tabular}{|l|l|l|l|l|l|}
\hline & NB & N & Z & P & PB \\
\hline NB & NB & NB & NB & P & PB \\
\hline N & NB & N & N & Z & PB \\
\hline Z & N & N & Z & P & PB \\
\hline P & Z & N & P & P & PB \\
\hline PB & Z & P & PB & PB & PB \\
\hline
\end{tabular}

Table 5. Fuzzy Rules of KD Gain. 


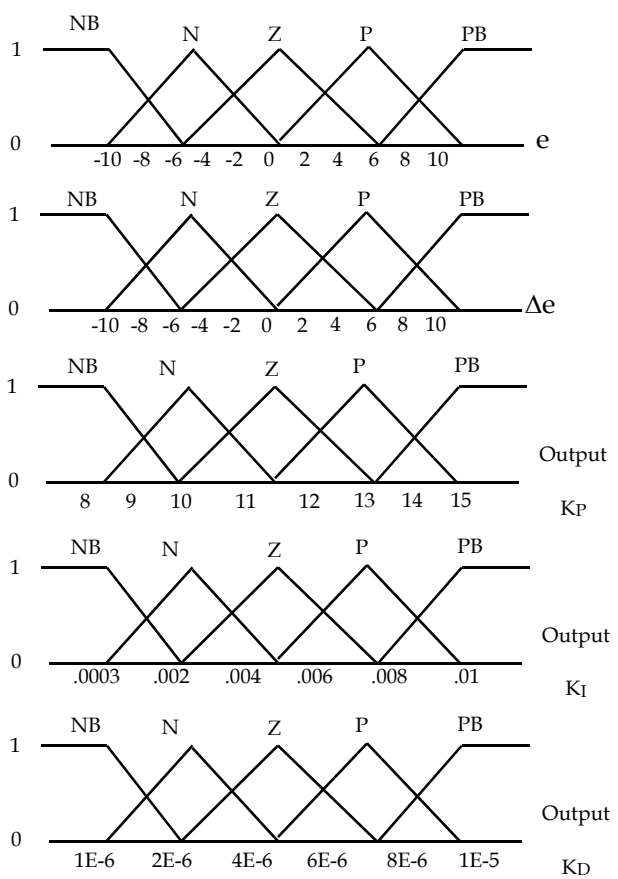

Figure 11. Fuzzy sets of a fuzzy self-tuning PID controller.

\subsection{Hybrid of fuzzy and fuzzy self-tuning PID controller}

A hybrid of fuzzy and fuzzy self-tuning PID controller, as shown in Figure 12, was developed to combine the advantages of both fuzzy and PID controller together. In addition, the adjustment gain of PID with a fuzzy tuner is included to purposed controller also, which all of these described in section 4.1, 4.2, 4.3, and 4.4.

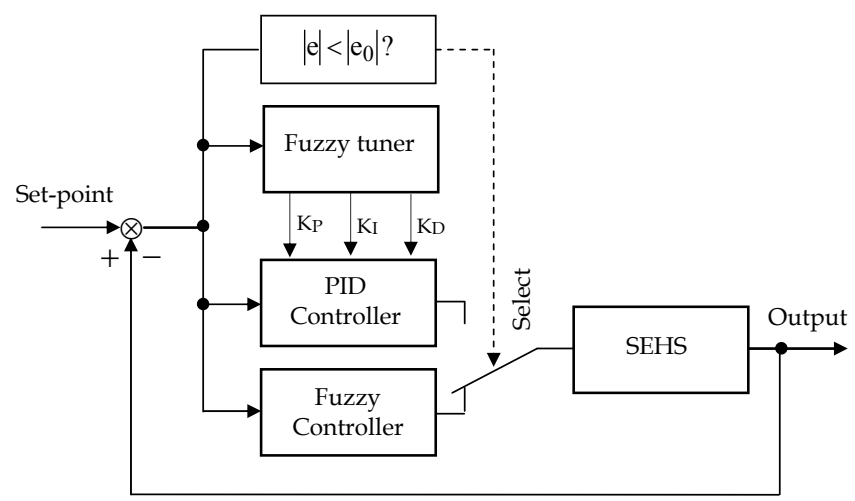

Figure 12. Block diagram of a fuzzy self-tuning PID controller. 


\section{The experimental results}

The effectiveness of the proposed hybrid of fuzzy and fuzzy-tune PID controller is evaluated experimentally with the SEHS and is compared with that of the hybrid fuzzy PID controller which uses the nominal values of the gains obtained by experiment. The control algorithms described in section 4.1,4.2, 4.3, and 4.4 were hybridized and applied to the SEHS using by LabVIEW program as the development platform and shown in Figure 13.

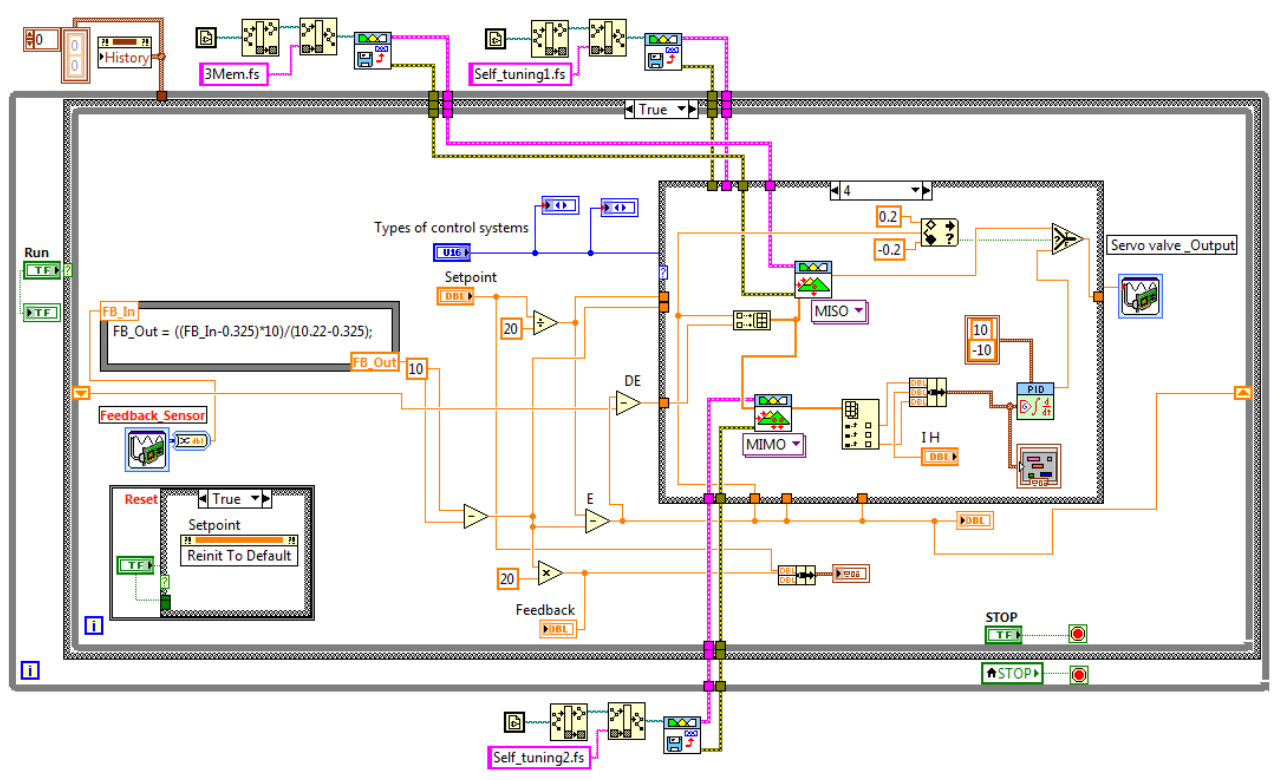

Figure 13. The control algorithms are developed by LabVIEW program.

The proposed of a hybrid of fuzzy and fuzzy self-tuning PID controller is evaluated experimentally with the motor speed control of SEHS and is compared with that of the conventional of a hybrid of fuzzy and PID controller. For the first experiment to observe the response of the SEHS control output of the both controller, which shown in Figure. 14 and Table 6, respectively. Then, change the parameters of the SEHS, because existing experimental set is difficult to change the load so that this change in pressure of the SEHS instead. The change in pressure will make many values, but the parameters of the both controller still use the original setting from the previous first. Figure 14, Table 6, and Figure 15, Table 7 show examples of the responses of the output of the both controller, which resulted from changing the original value of system pressure are $50 \mathrm{bar}$ and 10 bar pressure. However, all these experiments the value of $e_{0}$ which is used as a reference in the selection of a controller is set at 0.92 that is the optimum value from experiment.

When the experiment has changed the parameters of the SEHS will find that the hybrid of fuzzy and fuzzy self-tuning PID would lead to a satisfactory response over the hybrid of 
fuzzy and PID controller. This is because the proposed controller does not require to adjustment the new parameters of PID controller although the parameters of the SEHS will change.

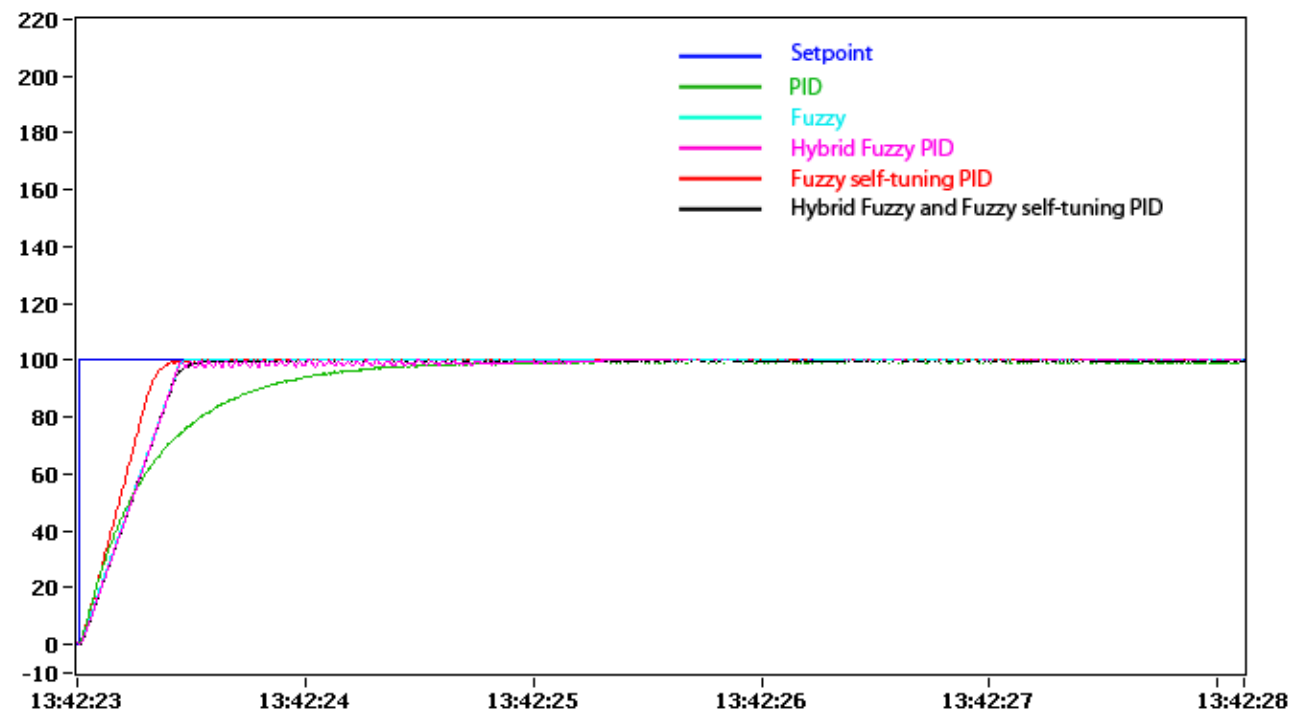

Figure 14. Comparison of the results of the five controls when the pressure was set at 50 bar

\begin{tabular}{|c|c|c|c|c|c|c|c|}
\hline \multirow[b]{2}{*}{ Controller } & \multirow[b]{2}{*}{$\begin{array}{l}\text { Velocity } \\
\text { (rpm) }\end{array}$} & \multicolumn{2}{|c|}{ Results } & \multirow[b]{2}{*}{$\begin{array}{l}\text { P.O. }=\frac{M_{O}}{F_{v}} \times 100 \\
\% \text { Overshoot }\end{array}$} & \multirow[b]{2}{*}{$\begin{array}{c}\text { Rise time } \\
\left(\mathrm{T}_{\mathrm{r}}\right)(\mathrm{s})\end{array}$} & \multirow[b]{2}{*}{$\begin{array}{l}\text { Time } \\
\text { delay } \\
\left(\mathrm{T}_{\mathrm{d}}\right)(\mathrm{s})\end{array}$} & \multirow[b]{2}{*}{$\begin{array}{c}\text { Settling } \\
\text { Time } \\
\left(\mathrm{T}_{\mathrm{s}}\right)(\mathrm{s})\end{array}$} \\
\hline & & $\begin{array}{c}\text { Velocity } \\
\text { (rpm) } \\
\text { Output }\end{array}$ & Error & & & & \\
\hline PID & $0-100$ & 99.932 & 0.003 & 0 & 0.675 & 0.25 & 2.15 \\
\hline Fuzzy & $0-100$ & 99.919 & 0.004 & 0 & 0.325 & 0.25 & 0.5 \\
\hline $\begin{array}{l}\text { Hybrid } \\
\text { Fuzzy PID }\end{array}$ & $0-100$ & 99.952 & 0.002 & 0 & 0.325 & 0.25 & 2.6 \\
\hline $\begin{array}{l}\text { Fuzzy Self- } \\
\text { tuning PID }\end{array}$ & $0-100$ & 99.860 & 0.006 & 0 & 0.25 & 0.2 & 0.525 \\
\hline $\begin{array}{l}\text { Hybrid } \\
\text { Fuzzy and } \\
\text { Fuzzy self- } \\
\text { tuning PID }\end{array}$ & $0-100$ & 99.552 & 0.022 & 0 & 0.325 & 0.2 & 0.525 \\
\hline
\end{tabular}

Table 6. Comparison of the results of the five controls when the pressure was set at 50 bar. 


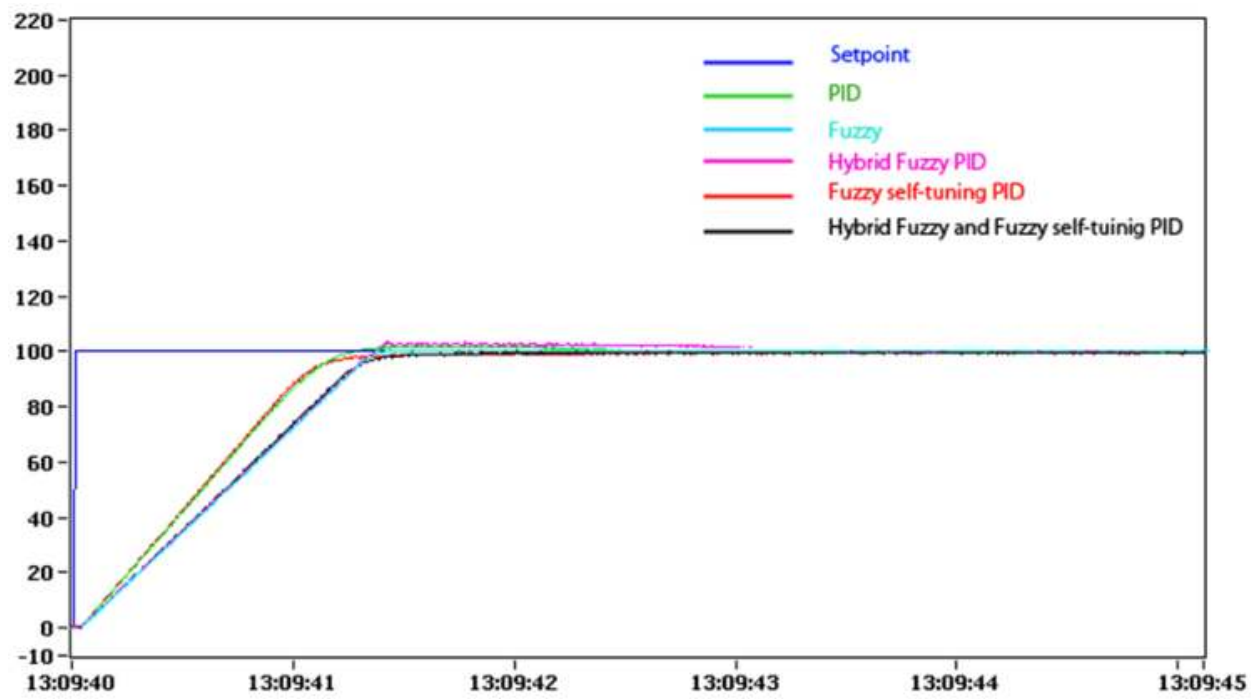

Figure 15. Comparison of the results of the five controls when the pressure was set at 10 bar

\begin{tabular}{|l|c|c|c|c|c|c|c|}
\hline \multirow{2}{*}{ Controller } & \multirow{2}{*}{$\begin{array}{c}\text { Velocity } \\
(\mathrm{rpm})\end{array}$} & $\begin{array}{c}\text { Velocity } \\
(\mathrm{rpm}) \\
\text { Output }\end{array}$ & Error & $\begin{array}{c}\text { R.O. }=\frac{M_{O}}{F_{o}} \times 100 \\
\% \text { Overshoot }\end{array}$ & $\begin{array}{c}\text { Rise time } \\
\left(\mathrm{T}_{\mathrm{r}}\right)(\mathrm{s})\end{array}$ & $\begin{array}{c}\text { Time } \\
\text { delay } \\
\left(\mathrm{T}_{\mathrm{d}}\right)(\mathrm{s})\end{array}$ & $\begin{array}{c}\text { Settling } \\
\text { Time } \\
\left(\mathrm{T}_{\mathrm{s}}\right)(\mathrm{s})\end{array}$ \\
\hline PID & $0-100$ & 99.697 & 0.015 & 2.5 & 0.875 & 0.55 & 2.45 \\
\hline Fuzzy & $0-100$ & 99.874 & 0.006 & 0 & 1 & 0.7 & 1.7 \\
\hline $\begin{array}{l}\text { Hybrid } \\
\text { Fuzzy PID }\end{array}$ & $0-100$ & 99.889 & 0.001 & 3 & 1 & 0.7 & 3.05 \\
\hline $\begin{array}{l}\text { Fuzzy Self- } \\
\text { tuning PID }\end{array}$ & $0-100$ & 99.513 & 0.024 & 0 & 0.825 & 0.55 & 2.6 \\
\hline $\begin{array}{l}\text { Hybrid } \\
\text { Fuzzy and } \\
\text { Fuzzy self- } \\
\text { tuning PID }\end{array}$ & $0-100$ & 99.847 & 0.007 & 0 & 1 & 0.4 & 1.8 \\
\hline
\end{tabular}

Table 7. Comparison of the results of the five controls when the pressure was set at 10 bar.

\section{Conclusions}

The objective of this study, we proposed the hybrid of fuzzy and fuzzy self-tuning PID controller for motor speed control of a SEHS. The proposed control scheme is separated into two parts, fuzzy controller and fuzzy self-tuning PID controller. Fuzzy controller is used to control systems when the output value of system far away from the target value. Fuzzy selftuning PID controller is applied when the output value is near the desired value. In the terms of adjusting the PID parameters are tuned by using fuzzy tuner as to obtain the 
optimum value. We demonstrate the performance of control scheme via experiments performed on the motor speed control of the SEHS. The results from the experiments show that the proposed a hybrid of fuzzy and fuzzy self-tuning PID controller has superior performance compared to a hybrid of fuzzy and PID controller. This is because the proposed controller does not require to readjustment the parameters of PID controller although the parameters of the SEHS will change any.

\section{Author details}

Kwanchai Sinthipsomboon, Issaree Hunsacharoonroj and Josept Khedari, Rajamangala University of Technology, Rattanakosin, Thailand

Watcharin Po-ngaen and Pornjit Pratumsuwan

King Mongkut's University of Technology North Bangkok, Thailand

\section{Acknowledgement}

The authors would like to thank USE FLO-LINE Co., Ltd. and mechatronics educational research group for their equipments and technical support of this research project.

\section{References}

Merrit, H.E., "Hydraulic Control System”. John Wiley, New York, 1976.

Rong-Fong Fung, Yun-Chen Wang, Rong-Tai Yang, and Hsing-Hsin Huang., “A variable structure control with proportional and integral compensatios for electrohydraulic position servo control system," Mechatronics vol.7, no. 1, 1997, pp. 67-81.

M. Aliyari, Shoorehdeli, M. Teshnehlab, and Aliyari Shoorehdeli., "Velocity control of an electro hydraulic servosystem," IEEE, 2007, pp. 1536-1539.

Parnichkun, M. and C. Ngaecharoenkul., "Hybrid of fuzzy and PID in kinematics of a pneumatic system," Proceeding of the 26th Annual Conference of the IEEE Industrial Electronics Society, Japan, 2000, pp: 1485-1490.

Pornjit Pratumsuwan, Siripun Thongchai, and Surapan Tansriwong., "A Hybrid of Fuzzy and Proportional-Integral-Derivative Controller for Electro-Hydraulic Position Servo System" Energy Research Journal, vol. 1,issue 2, 2010, pp. 62-67.

Jianming Zhang, Ning Wang, and Shuqing Wang., "Developed method of tuning PID controllers with fuzzy rules for integrating processes," Proceeding of the 2004 American control Conference, Massachusetts, 2004, pp. 1109-1114.

Shoujun Song and Weiguo Liu.,"Fuzzy parameters self-tuning PID control of switched reluctance motor based on Simulink/NCD," CIMCA-IAWTIC'06, IEEE, 2006.

Zulfatman and M.F. Rahmat.., "Application of self-tuning fuzzy PID controller on industrial hydraulic actuator using system identification approach," International journal on amart sensing and intelligent system, vol. 2, no. 2, 2009, pp. 246-261. 
314 Fuzzy Controllers - Recent Advances in Theory and Applications

Bin Feng, Guofang Gong, and Huayong Yang.,"Self-tuning parameter fuzzy PID temperature control in a large hydraulic system," International Conference on Advanced Intelligent Mechatronics, IEEE/ASME,2009, pp.1418-142 